\title{
Challenges of using reflective teaching approaches in Civic Education lessons in secondary schools in Lusaka, Zambia
}

\author{
Pamela Shimanza* \& Gistered Muleya \\ The University of Zambia, School of Education, Department of LSSE, P.O Box, 32379, Lusaka, ZAMBIA \\ Corresponding Author* \\ DOI: https://dx.doi.org/10.47772/IJRISS.2021.5326
}

\begin{abstract}
The teaching and learning of Civic Education helps learners recognize the profound role that the subject plays in society. This study sought to establish the challenges associated with the use of reflective teaching approaches in Civic Education lessons. The study was guided by a qualitative approach and the research strategy used was a descriptive design. Data was collected using a reflective questionnaire and lesson observation checklist. Purposive sampling was used to identify the participants in the study. The participants included 6 deputy head teachers, 6 Civic Education heads of section, 6 social sciences heads of department and 18 Civic Education teachers. Data collected was thematically analysed. The total number of the participants in the study amounted to 36 . The findings of the study revealed that time allocation, large numbers in classes, lack of participation from learners were inhibiting the use reflective teaching in Civic Education lessons.This research study is insightful because it adds to the body of knowledge about the challenges of using reflective teaching approaches in civic education lessons. The study concludes that most teachers of Civic Education need to be trained in reflective teaching approaches to improve the teaching and learning of Civic Education.
\end{abstract}

Key words: Reflective teaching, Civic Education

\section{INTRODUCTION}

$\mathrm{T}$ eaching is a complex profession which requires teachers to question their practices for their own professional development and to increase learner performance (Sifuniso, 2015; Yates and Muchisky, 2003). The teaching of Civic Education introduces learners to the critical dimensions of life of the society by looking at the social, economic, technological and political developments underpinning the society.Reflective teaching in secondary schools is a major concern in many countries of the world (Abkari, 2007), Zambia inclusive. According to Farrell (2001) reflection is defined as a carefully planned set of experiences that foster a sensitivity to ways of looking at and talking about previously unarticulated beliefs concerning teaching. Hoover holds the view that reflection is a systematic practice that can be learned from the past experiences one has had (Farrell, 2001). Therefore, reflective teaching approach is an inquiry-based approach to teaching that involves critical thinking and a personal commitment to continuous learning and improvement. It involves thinking about and critically analysing one's own teaching to improve teaching and learning.

A few studies such as those done by Benson et al (2001) and Disu (2017), analysed the use of reflective practice to improve teaching and learning. As shown by Disu (2017), through reflectiveteaching teachers are able to examine their teaching, assess level of assimilation by learners, and test theories to gain new perspective on their classroom experiences. A study conducted by Sharafi and Rokni (2014), gives a detailed examination of reflection in pre-service teacher education in Iran. The study revealed that there was a development process in pre-service teachers' reflectivity in the English course but did not look at challenges associated with the use of reflective teaching approaches in civic education.

Some scholars believe that reflective teaching forms a cornerstone for critical thinking (Cornford, 2002; Pollard, 2006; Rayford, 2010). It is believed that it is quite possible for teachers to liberate themselves from the confinements of the classroom by "questioning and then replacing or reframing an assumption which is accepted as representing dominant common sense by a majority" (Behzadpour, 2011). However, the challenges encountered to achieve this level is not known.

Reflective practice is important as it enables teachers to learn from experiences of teaching and facilitate students' learning. The approaches bring together theory and practice as they enable a person to reflect on what is being taught and to see and label forms of thought and theory within the context of his or her work. A person who reflects throughout his or her practice is not just looking back on past actions and events, but is taking a conscious look at emotions, experiences, actions, and responses, and using that information to add to his or her existing knowledge base and reach a higher level of understanding (Mathew et al, 2017). Nevertheless, the challenges encountered to reach this level especially in civic education are not known.

Hadiya (2017)'s study asserted that many significant classroom events may not have been observed by the teacher, let alone remembered, without the use of reflective teaching approaches. It can trigger teachers' reflective thinking, reflect on their weaknesses and help them get some inspiration and 
ideas for their teaching improvement. Another study done by Mupa and Chinooneka (2015) revealed that contact with experienced teachers in the New South Wales secondary system showed anecdotal evidence of a major concern by many at the overly high levels of confidence displayed by many student teachers exposed to reflective practices. These student teachers were very frequently judged by experienced teachers as being over-confident with this apparently impeding their ability to benefit from advice or even obvious classroom failures.However, most of the recent studies attest to the significance of reflective teaching approaches in lesson delivery and teacher education.

Ganyaupfu (2013)'s study on the differential effectiveness of teaching methods on students' academic performance in South Africa reveals a number of types of reflective teaching which can help in learner achievements. Similarly, Bassey et al (2014), explored the appropriate pedagogy that can be employed for the teaching and learning of social studies and Civic Education by the social studies teachers in Nigeria. However, nothing was discussed with regards to the challenges encountered with the use of reflective teaching approaches in lesson delivery.

Mathew et al (2017) conducted a study in India where he examined how the teacher educators created opportunities for student teachers to develop their reflective practices during their teaching practice seasons. They stressed that teaching approaches are closely related to the students' achievements and therefore, proper instructional methods used in schools will influence academic achievement among learners. The study concludes that reflective practice leads to professional development among teachers and therefore student teachers must be given opportunities to explore the pedagogy on their own. Similarly, the study that was done by Benson et al (2001), in Australia suggest that demands by the accounting profession for universities to improve learning to cope with the ambiguity and uncertainty inherent within professional life can be met by reflective practice.

A phenomenological study on reflective teaching practice done by Disu (2017) in Portland revealed that teachers use reflective teaching practice to create meaning from their classroom experiences and enact necessary steps toward improvement. Through reflective teaching practice, participants were able to examine their teaching, assess students' learning, seek new ideas, and test theories to gain new perspectives on their classroom experiences.This coincides with the aims of reflective teaching where the teacher engages learners in questioning class activities.

Ogweno (2010), further conducted a study on the influence of teaching approaches on students' achievement in English in public secondary schools in Kenya. The study found that text book reading, demonstration and homework assignment were the most used methods. An investigation into the methods most liked by the learners revealed that some of the most used methods by the teacher are not the most liked by the learners hence the need for teachers to practice reflection. The study also revealed that teachers who are highly experienced were identified by the methods which have more activities and that allow teacher-learner interaction. The study noted that teachers who used methods with hands on activities (student centred) had their students score highly.

Sifuniso (2015)'s study on the implementation of reflective teaching methods in primary schools in Livingstone district of Zambia, revealed some disparities in the implementation of reflective teaching among teachers. She found that factors that hindered implementation of reflective teaching methods, included time limitations, curriculum needs and class size. Although teachers were aware of the importance and relevance of reflective teaching, observations showed that they had difficulties to practice the same in their classes due to limited time, curriculum needs, and class size. However, this study did not look at the influence of reflective teaching on learners in Civic Education lessons.

Another study done by Muleya (2015), examined the trends in the teaching of Civic Education in Zambian schools. The study examined pedagogical practices in relation to the teaching of Civic Education in schools and argues that following right pedagogical practices in the teaching of Civic Education can lead to social change and transformation of society. However, the challenges of using reflective teaching approaches of reflective in Civic Education lessons was not looked at. Reflective practice has therefore become a focus of interest and a powerful movement in the education sector.

It is clear from the studies reviewed that the reflective teaching if well practiced can have an influence on student learning. With regards to the challenges of using reflective teaching approaches in Civic Education lessons, the study results are mixed.Nonetheless, it is important to state that even though several studies on reflective teaching have been undertaken, not much can be found with regards to the subject of Civic Education. It is from this background that this study aimed at establishing the challenges faced by secondary school teachers in the use of reflective teaching approaches in Civic Education lessons in Zambia to fill the above information gap.

\section{Statement of the Problem}

Given the demand for quality education and need for better educated citizens, numerous studies have been done on the use of reflective teaching in various subjects (Sifuniso, 2015 and Disu, 2017).Nonetheless, it is important to state that even though several studies on reflective teaching have been undertaken, not much can be found with regards to the subject of Civic Education. Thus, teachers have continued to routinely do their work and one is left to wonder whether they reflect on their teaching or they face challenges while using reflective teaching approaches. Further, there seemed to be no study which examined the challenges of using reflective teaching approaches in Civic Education lessons in secondary schools in 
Zambia. If this trend continues, teachers are likely to continue teaching without paying attention to key variables such as reflective teaching and this will not help the learners to become creative, innovative and critical thinkers once they are out of school. It was therefore imperative to see whether Civic Education teachers face challenges while using reflective teaching approaches during lesson delivery. If they do, how can such challenges be addressed? This is a gap in literature that needs to be filled. This study therefore, sought to examine the challenges of using reflective teaching approaches in Civic Education lessons.

\section{THEORETICAL FRAMEWORK}

This study was guidedby Kolb's 1984 Experiential Learning Theory (ELT) (Kolb,1984).The theory of experiential learning gives a useful model by which to develop the teaching practice. Experiential learning theory works on two levels: a four-stage cycle of learning and four separate learning styles. The cycle comprises four different stages of learning from experience and can be entered at any point, but all stages must be followed in sequence for successful learning to take place. With reflective teaching therefore, teachers of Civic Education can help learners to apply the knowledge they gain in class in real life situations. All this will lead to the next concrete experience. This can happen over a short duration or over a long duration of time.

Reflective practice is important to the development of teachers of Civic Education as it enables them to learn from their experiences of teaching and facilitating student learning. Developing reflective practice means developing ways of reviewing teaching so that it becomes a routine and a process for continuously development (Gebhardt, 2005). The theory further helps the teacher to develop more appropriate learning opportunities for the learners and to design activities that can give opportunities to all the learners to learn in the best way which suits them. It was therefore imperative to interrogate this theory in the way teachers of Civic Education use reflective teaching approaches to ascertain the challenges they encounter while using the approaches.

\section{RESEARCH METHODOLOGY}

To fulfil the aim of this study, the qualitative research paradigm was used. This was done using the descriptive design. Descriptive research seeks to provide an accurate description of observations of a phenomenon. Using this design, the study examined full context and interactions with participants while collecting most data face- to- face from participants and doing lesson observations. A descriptive design can be used when collecting information about peoples' attitudes, opinions, habits or any of the variety of education or social issues (Orodho and Kombo, 2002). It helps describe the state of affairs as they exist. Furthermore, descriptive studies are not only restricted to fact findings, but may often result in the formulation of important principles of knowledge and solution to significant problems.
The study population was drawn from six (6) secondary schools in Lusaka district. The study population refers to study population as the list or record of individuals in a population that a researcher obtains for a study(Creswell 2012). The target population in this study comprised 18 Civic Education teachers, 6 Heads of Department, 6 Civic Education heads of sections and 6 deputy head teachers totalling 36 participantsin selected secondary schools in Lusaka district where civic education is offered. Lusaka district is one of the eight (8) districts in Lusaka province. This area of the study was selected because it is among the areas where civic education programme was initially piloted prior to its introduction as a high school subject. Secondly, the choice was also made due toseveral discrepancies in the performance of learners in civic educationin Lusaka district. This study therefore sought to examine challenges faced by teachers while using reflective teaching approaches in civic education lessons in six selected schools in Lusaka district.Data was collected using in-depth semi structured interviews for Deputy head teacher, social sciences head of department and Civic Education head of section, a reflective questionnaire for Civic Education teachers and a lesson observation checklist. The other instrument that was used was the lesson observation checklist. Data was analysed thematically.

\section{Ethical considerations}

An ethic is a moral principle or a code of conduct which guides what people do (Wellington, 2000). Ethical issues involve the issues of informed consent to allow the respondent to participate and disclose information willingly without any interferences (Cohen et al, 2011). The researcher adhered to research ethics by applying for ethical clearance through the Ethical Committee of the University of Zambia to be granted permission to proceed in undertaking the study. This was done in accordance with the provisions of the Directorate of Research and Graduate Studies. The participants in this comprised deputy head teachers, HoDs, HoS, and Civic Education teachers in secondary schools in Lusaka district.

\section{Informed consent}

The researcher sought informed consent from the participants. Informed consent is a communication between the researcher and the participants. The researcher informed the participants the advantages of being part of the study. Permission was sought from the District Education Board Secretary (DEBS) in order for the researcher to freely interact with head teachers and civic education teachers.

\section{Research description}

The researcher had a duty to ensure that the participants are aware of the purpose of the study. The researcher informed the participants the purpose of the study and asked for their wilfully participation in the study. 


\section{Benefits and risks}

Participants were informed that positive participation in this study was expected as it could help improve the teaching and learning in civic education for the benefit of the learners. However, the participants were also told that participation in this study was not to subject them into any form of risk as the data to be collected was for academic purposes only.

\section{Anonymity and confidentiality}

Considering the significance of ethical issues in every research, in this study responses from participants were treated with maximum confidentiality as the data was used purely for academic purposes. The participants who included the head teachers, teachers of civic education, heads of department and heads of section were asked not to write their names and that of their schools on the research instruments.

\section{Voluntary participation}

Furthermore, the researcher ensured that the participants were treated with all the respect they deserved. It was imagined that there would be no form of coercion or influence on the participants to respond against their will (Dooley, 2001). To gain the goodwill of the participants, the researcher tried by all means to establish a good rapport with them before the day of the meeting. The participants were also asked to feel free to withdraw from the study at any time if they felt that they could not give the needed information

\section{FINDINGS AND RESULTS}

\section{Knowledge of reflective teaching among teachers}

The study revealed that there was lack of understanding of the reflective process among civic education teachers making them not to practice the teaching approach.

One civic education teacher said:

I have heard of reflective teaching approaches but I don't really know how it can be done in the teaching of civic education or just the teaching process itself

\section{Education authority activities}

Most respondents alluded to emphasis on syllabus coverage by the education authorities as one of the hindrance to the use of reflective teaching.

One deputy head teacher said:

There is just too much emphasis on syllabus coverage whenever inspectors visit the school without paying attention on the modes of covering the syllabuswhich makes it difficult for teachers to reflect on their teaching.

A similar sentiment was put forward by one Civic Education head of section who said:

most of the time the school put emphasis on what has been covered in the syllabus and not really the methods used to teach the subject. So, we rarely make use of certain teaching approaches because our focus is usually on curriculum and not how we teach...

Similarly, most of the teachers interviewed said that there was so much emphasis on curriculum coverage by the ministry of education and hence paying less attention to the approaches used. One teacher stressed that:

The is so much forcing of syllabi completion especially for grade $12 \ldots$ time and again we see officers from the ministry just to come and check how far we have gone with the syllabus. So basically, it's all about exams.

\section{School Schedules}

Study revealed that most teachers of Civic Education are unable to use reflective teaching approaches due to schedule of activities made by their schools such as time allocated to the subject. Time allocated to Civic Education was said to be inadequate and was found to be 4 periods (160 minutes per week)

One of the teachers from school A stated that:

class organisation is difficult, time allocated to teach civic education is usually not adequate, especially junior classes where we teach for a single period making it difficult to use other teaching strategies.

Similarly, one of the HODs said that:

we have so many subjects to timetable and very few teachers to teach and so you find one teacher moving from one class to another...they have no time to reflect because the work load is too much, and time is limited especially now that Civic Education is compulsory in schools.

One deputy head teacher also revealed that:

There is so much curriculum demand from our end such that time allocated to teach each subject can't allow the use of some teaching strategies like reflective teaching...to effectively use this strategy is not possible in these public institutions, may be in private schools.

\section{Unplanned activities}

It was discovered that unplanned activities such as over enrolment was an obstacle to the use of reflective teaching as it posed a challenge for teachers to pay attention to individual learners. One of the deputy head teachers had this to say:

like you have seen for yourself in some classes you went to and found about 90 pupils in one class...this is because we are forced to enrol as much as we can without considering the number of teachers and classroom space. Because of large number of pupils in class it becomes difficult for teachers to use methods like the one you are talking about".

A teacher added by saying that: 
Over enrolment makes it difficult to teach them using strategies like field trip, group work and debate which are reflective in nature...it is not that we do not want to use reflective teaching approaches, it's the number of pupils we handle per class which cannot allow.

Another said that:

Schools should reduce numbers in class to help teachers to attend to individual needs of learners within the class and be able to use reflective teaching effectively.

\section{Lack of participation from the learners}

The study revealed that there was less participation from the learners which somewhat made it difficult for Civic Education teachers to use the reflective teaching approach effectively. To solidify these findings, a teacher from School C said that:

Lack of full participation from learners due to large numbers in class poses a big challenge... hence pupils rarely participate in their learning and this makes it difficult for us to know the challenges learners face in grasping what we teach. Even when you ask for feedback from them, only a few or none will respond.

If you give homework and tell them to go and research, very few will do the work. Majority will say they are busy at home, others say there is no one to help them do the work at home...in short we are trying as teachers, but the pupils are not helping us because they rarely participate in their learning.

\section{DISCUSSION AND IMPLICATION}

Findings of the study were discussed as follows:

Challenges associated with the use of reflective teaching approaches in civic education lessons

The study revealed that lack of knowledge of reflective process, insufficient time allocation, large numbers in classes, emphasis on syllabus completion rather than knowledge acquisition, lack of participation from learners were inhibiting the use of reflective teaching approaches in Civic Education lessons. Although most teachers were aware of the importance and relevance of reflective teaching, observations showed that they had difficulties to practice the same in their classes due to limited time.

\section{Knowledge of reflective teaching among teachers}

Lack of understanding of the concept of reflective teaching among teachers was revealed as one of the limiting factors in use of reflective teaching approaches in Civic Education lessons. The concept of reflective teaching was viewed differently by the participants. The study found out that not all teachers were aware of reflective teaching approaches and hence the differences in understanding the concept. Participants in this study defined Reflective Teaching approach as a process where teachers think over their teaching by analysing how a lesson was delivered in order to make adjustments for better learning outcomes. This is in line with
Kolb (2014), who defined reflective teaching as a process where teachers think over their teaching practices, analysing how something was taught and how the practice might be improved or changed for better learning outcomes.

Unlike Akbari (2007)'s study which established that teachers improve their understanding and use of reflective teaching approaches by reflecting critically on their teaching experiences, this study established that not all teachers are knowledgeable of reflective teaching approaches and hence do not use the approach despite being in the teaching professional for long period of time. In line with the theory used in this study, this scenario can have an implication in the teaching and learning of Civic Education by producing half-baked learners as teachers will not be paying attention to the ideals of teaching advocated in the experiential learning theory. Mathew (2017), further supports this view by arguing that experience alone does not lead to reflective teachers but deliberate reflection on experience.

\section{Time limitation}

This study revealed that practicing reflective teaching was time consuming considering the insufficient time allocated to teaching of Civic Education. Although most teachers were aware of the importance and relevance of reflective teaching, observations showed that they had difficulties to practice the same in their classes due to limited time. These limitations were also observed by Sifuniso (2015) who argued that most teachers were unable to use reflective teaching due to limited time allocated to various subjects. Additionally, the study revealed that some teachers do not have the skills to apply effectively the reflective teaching approaches as they said it was time consuming.

\section{Over - enrolment}

Large numbers in class were another impediment to the use of reflective teaching approach that was discovered during this study. According to Wilson (2006), the methods that teachers could use in large classes are not as plentiful as those available to teachers in small classes. There is some truth in this statement in that in small classes, teachers are able to practice a variety of methods, such as learning centres, higher order questioning, and other active-learning approaches. It was observed that teachers with smaller classes were able to use reflective teaching unlike those handling larger classes because these learners require the individual attention only available from a teacher in a small class. Thus, it becomes clear why teachers generally are of the opinion that reflective teaching can only work in smaller classes because large classes do not allow scope to realise individualised instruction. Ehrenberg et al (2001) noted that the number of students in a class has the potential to affect how much was learnt in a number of different ways. It could affect the social engagement of students and it could also result in less or more noise and disruptive behaviour. 
Results on the effectiveness of teachers in class as compared to the numbers they handle are consistent with the study conducted Mathew et al (2017), who posited that the methods that teachers could use in large classes are not as plentiful as those available to teachers in small classes. In small classes, teachers can practice a variety of methods, such as learning centres, higher order questioning, and other active-learning approaches. It was observed that teachers with smaller classes were able to use reflective teaching unlike those handling larger classes because these learners require the individual attention only available from a teacher in a small class.

Thus, it becomes clear why teachers generally believe reflective teaching can only work with few students and it could also result in less or more noise and disruptive behaviour. In addition, it could as well affect how much time the teacher was able to focus on individual students and their specific needs rather than the big class. For these reasons, changes to the class size were considered a potential means of changing how much is learnt. Since reflective teaching is about learners discovering for themselves information usually about themselves - how they respond to things, what their feelings are, how to handle their feelings and their opinions, the teacher need to pay attention on the level of progression among individual learners. They learn this through the reflection on the experience.

This however conflicts with the theory of experiential learning which urges teachers to make teaching take place by devising new ways of overcoming any challenges encountered during the teaching process. Teachers should design activities that will give opportunities to all the learners to learn in the best way that suits them despite the numbers in class. The point about experiential learning is that that the learning comes from the experience itself. It is about learners discovering for themselves information and how they respond to things, what their feelings are, how to handle their feelings and their opinions. They learn this through the reflecting on their experiences. The teacher in the learning process is viewed as a facilitator only and therefore large numbers should not be seen as a limitation.

The traditional way of teaching encourages dependence, encourages the learner to rely on the teacher for what to think and how to think. Compliance is rewarded, and so independent and original thinking is not developed.In experiential learning the learner is encouraged to think for himself/herself, not to repeat the thought patterns of the teacher. This means that the teacher (facilitator) - learner relationship is very different. Therefore, the challenges identified in this study can only be addressed when teachers begin to understand reflective teaching and apply it in their day to day activities. It is a more equal, open relationship with the facilitator standing metaphorically beside the learner providing support and constructive feedback rather than criticism or rewards. Having used this theory in the context of the current study, the researcher is of the view that this could work towards the improvement of the teaching and learning of Civic Education in secondary schools.

\section{CONCLUSION}

The study further concludes that time allocation, large numbers in classes, lack of participation from learners were somewhat inhibiting reflective teaching in Civic Education lessons.Therefore, the teaching and learning of Civic Education can only improve if teachers are to pay attention to reflective teaching approaches. If teachers do not improve on the use of reflective teaching approaches, the goals and aims of Civic Education will not be realised and the learners too will not become innovative and critical thinkers once they are out of school. Further, learners will not be equipped with vital knowledge, skills and values that are necessary to attainment of vision 2030. With reflective teaching therefore, teachers of Civic Education can help learners to apply the knowledge they gain in class in real life situations

\section{RECOMMENDATIONS OF THE STUDY}

Based on the findings, the following recommendations are made:

1. Government should encourage colleges of education to incorporate reflective teaching approaches as a component in teaching methodologies and encourage teachers of Civic Education to have a positive attitude towards reflective teaching.

2. School management should also give adequate time and space for the practice of reflective teaching in Civic Education lessons in secondary schools

\section{REFERENCES}

[1] Abimbade, A. and Afolabi S.S., (2012). 'A Study of Pedagogical Approaches of Mathematics Teaching in Southwestern States of Nigeria.' In International Journal of Asian Social Science, 2(8), pp. 1182-1192.

[2] Adebayo, A. S. and Zimba, F. L., (2014). 'Perceptions of teachers and learners on the effectiveness of civic education in the development of civic competency among learners in Chipata district, Zambia'. In European Scientific Journal. 10 (7), pp. 1857 $-7881$

[3] Akbari, R., (2007). 'Reflections on Reflection: A Critical Appraisal of Reflective Practices'. In Teacher Education System, 35 (2), pp. 192-207.

[4] Creswell, J.W., (2009). Research Design: Qualitative, Quantitative and Mixed Methods Approaches. London: Sage publication.

[5] Disu, A., (2017). A Phenomenological Study on Reflective Teaching Practice. Ph. D Thesis. Concordia University - Portland.

[6] Examination Council of Zambia, (2015). 2015 Examinations Performance Report. General Performance Analysis.

[7] Examination Council of Zambia, (2016). 2016 Examinations Performance Report. General Performance Analysis.

[8] Ehrenberg, R. G., Brewer, D. J., Gamoran, A. andWillms, J. D., (2001). The class size controversy. Cornell University; http://digitalcommons.ilr.cornell.edu/workingpapers/25

[9] Farrell, T., (2001). 'Tailoring Reflection to Individual Needs: a TESOL Case Study'. Journal of Education for Teaching, 27 (1), pp. 23-38.

[10] Fatemipour, H. and Hosseingholikhani, F., (2014). 'The impact of Reflective Teaching on the EFL Teachers' performance'. In Journal of Educational and Management Studies. 4 (4), pp. 796799 
[11] Gebhard, J. G., (2005). Teacher Development through Exploration: Principles, Ways, and Examples. Teacher Education Learning Journal, 9 (2), pp. 1-15.

[12] Hadiya, H., (2017). 'A study of reflective practice and its role for teachers", In international journal of creative research thoughts (IJCRT), 5 (4), pp. 944-947, issn:2320-2882.

[13] Kolb, D. A., (1984). Experiential Learning: Experience as the Source of Learning and Development. Prentice-Hall, Inc: Englewood Cliffs, N.J.

[14] Mathew, p., Mathew, p. and Peechattu, P.J., (2017). 'Reflective practices: a means to teacher development'. In Asia Pacific Journal of Contemporary Education and Communication Technology (APJCECT), 3 (1).
[15] Olan, J. F. and Hoover, L. A., (2008). Teacher Supervision and Evaluation: Theory into Practice (2nd ed.). New York: Wiley \& Sons.

[16] Orodho, J. A., (2009). Elements of Education \& Social Sciences Research Methods. Maseno: Kenezja Publishers.

[17] Sifuniso, M., (2015). An analysis of the implementation of reflective teaching methods in selected primary schools in Livingstone District of Zambia. Unpublished MA thesis. University of Zambia.

[18] Yates, R. and Munchisky, D. (2003). On conceptualising teacher education. TesolQuaterly, 37 (1), pp. 135-147. 